\title{
Theoretical Study of Reform and Innovate the Development of National Model Higher Vocational Education
}

\author{
Zhigang $\mathrm{Yu}^{*}$, Yang Chen, Shufang Li, Tianwei Yan \\ School of Civil Engineering \\ Chongqing Vocational Institute of Engineering \\ Chongqing 402260, China \\ *Corresponding Author
}

\author{
Jiaye $\mathrm{Wu}$ \\ Sichuan Central Inspection Technology Inc. \\ Chengdu 610045, China
}

\begin{abstract}
Return to "harmony" is the common tendency of educational reform all over the world. Harmony is a kind of highest beauty, and the education reform should advance the harmonious campus. Today, higher vocational education is popular, the students of vocational education should be trained both mental and physical skill. But also to be able to get involved in practice. They could grow up to skilled talent rapidly, so higher vocational education reform is imminent, the paper analyses the current situation and puts forward specific advice of strengthening "harmony" education and promoting the sustained development of the model higher vocational education in our country.
\end{abstract}

Keywords-model; education reform; harmonious education; higher vocational education

\section{INTRODUCTION}

The concept of harmonious education is transplanted and borrowed from the concept of ecological harmony in education. From the perspective of ecology, educational harmony is the balance of educational ecology. Harmonious campus refers to the harmonious, balanced and orderly developed situation of school. Campus harmony mainly refers to the various elements within the campus are in a state of interdependence, coordination and mutual promotion [1]. To build a harmonious campus is not only the need to adhere to scientific development and construct a harmonious society, but also the need to develop harmonious education and promote the comprehensive and coordinated development of school [2].

Harmonious campus comes from the harmonious management, and the coordination of educational behavior is inseparable from the innovation of management idea and the reform of management system [3-4]. With the popularization of higher vocational education, the reform of higher vocational education is urgent. Zhou Ji, former Minister of Education of China, emphasized in the 3rd National Higher Vocational Education Experience Exchange Conference on the Combination of Production, Teaching and Research that the

Chongqing Vocational Institute of Engineering "Top Ten Education" Quality Project, "Intelligent Civil Engineering"-Exploring the New Mode of Integration of Industry and Education under the Strategy of Transportation Power. Higher Vocational Education Double Base Construction Project of Chongqing Municipal Education Committee, Chongqing Vocational Institute of Engineering Construction Engineering Technology Specialty (Group) Double Base Construction Project. main task of higher vocational education is to cultivate talents with high skills. Such kind of talents are neither white-collar nor blue-collar, but are applied white-collar, which should be called "silver-collar". In the face of the present construction of national demonstrative vocational colleges, this paper puts forward to strengthen harmonious education, and based on the analysis of the current situation, it further puts forward advices to promote the sustainable development of demonstrative vocational colleges in China.

\section{PRESENT Situation AND DEVElopment SUGGESTIONS OF NATIONAL MODEL HIGHER VOCATIONAL EDUCATION}

\section{A. Improve Class Management Level, Show the Demonstration of Management}

Current situation: The full-time counselors are few, and few of them have professional background. There are many parttime counselors, and they adopt the traditional "preaching" mode in management. Many teachers are inexperienced or incompetent in the counselors' work and the assessment and incentive mechanism needs to be updated urgently. The professional teachers and part-time counselors of higher vocational colleges have made great achievements in their own research fields. These young teachers have active ideas, higher education, and rich professional background. However, most part-time counselors tend to be younger and are not good at ideological and political education and psychological counseling. They lack the theoretical basis and management experience of full-time counselors [5].

Suggestions are as follows: Each school and department should specially set up counselors' office and change to manage the class by full-time counselors' team. Establish supporting assessment and incentive mechanism. Incorporate it into the students' management research project of demonstration construction to strengthen the pilot research. Change thinking to gradually hire teachers who have professional background as the full-time counselors. Only having solid academic background, can the counselors give allround guidance in the professional knowledge and skills to the students, and help students understand the latest professional development, guide them in the professional studying, make 
career development plans, pay attention to students' employment and professional ability training. Cultivate skilled personnel in line with the requirements of the new era, and strengthen the professional quality training of counselors in the aspects of ideological and political education and mental health education.

\section{B. Strengthen the Role of the "Test" Baton, Show the Demonstration of Harmonious Campus}

Present situation: Many schools will arrange fixed classroom for freshmen in the first academic year. Usually, they will carry out daily management by teachers' name checking in class and the handlings of the department or school after the class, so as to ensure the teaching proceed normally. Teachers have formed a habit: as long as the students attend the make-up test, the teachers will let them pass the test, which made many students form a fixed thinking "mode". Suggestions are as followed: Lead the students to study actively through the baton of the test. The competition is very fierce and extremely realistic in the conduct of the baton, and the survival of the fittest is particularly clear. Millions of Chinese families have shown unprecedented attention and cohesion to the future of their children, and millions of Chinese students are also working hard to master knowledge better and faster in the struggle. We have to admit that this baton plays an important role in education. Pay close attention to the examination discipline, and give the chance of resits to the $3 \%$ $5 \%$ of the students in the make-up examination in each class. Any policy that explicitly states or implicitly states that is related to teacher assessment should be eliminated to ensure that teachers can implement smoothly. Gradually abolish the practice of arranging fixed classrooms for freshmen and promote the students in all grades to form the habit of selfstudy. Examine some rules and regulations that may affect the temporary economic benefits of the colleges from the perspective of the overall long-term harmonious development of the college.

As long as we start from one session of students, the next session of students will get a good "reputation" from the last session of students. Spread in the successive students and form a virtuous cycle. Mobilize their own subjective initiative, and consciously study happily in the competition, subsequently form a harmonious learning atmosphere and guide students to attend the self-studying class consciously.

\section{Strengthen the Comprehensive Quality Education of Students, Show the Demonstration of Employment}

Current situation: The connotation of "the students of higher vocational education should be able to use both their brains and hands, grow quickly and become high-skilled talents through the practical training" means that it is necessary to master certain theoretical and basic knowledge by "using brains", to have certain operation ability by "using hands" and to flexibly combine the specific problems existing in both theoretical knowledge and practical operation in quantities of practice, continuously explore and improve the insufficient by "growing quickly". One of the main differences between "higher vocational education" and "secondary vocational education" is reflected in the "quickly". If the students did not have a certain theoretical depth of knowledge, they cannot "grow quickly". At present, vocational colleges can provide certain theoretical and basic knowledge, but they cannot fully provide students with practical training base. Students' overall theoretical knowledge level is no high, and their practical ability cannot be effectively developed. The present employment situation is the imbalance between supply and demand and the great employment pressure. First, those have higher theoretical knowledge than the higher vocational college students are the students in better junior colleges, general undergraduate colleges and key undergraduate colleges. However, in the current transitional period of higher vocational college construction and under the situation that practical ability cannot be effectively ensured, we cannot highlight the characteristics of the strong practical ability of the higher vocational college students, so we cannot compete with them in employment. Second, the current employment contrast among higher vocational colleges is actually the employment rate resulting from the rationality of the professional setting, which is similar to the current employment situation among undergraduate colleges. Third, with the continuous severe employment pressure for many years, many college students have already made psychological preparation and have been able to face their employment situation. The jobs that many people feel hard and overqualified for them have become the popular "delicious cakes".

Suggestions are as followed: The general teaching and administrative staff should keep a high sober state and fully understand the current insufficient. The teaching staff should update their ideas to be the new type of teachers. They cannot always emphasize the "spirit of red candle"-burning themselves to light others. Nowadays, it is time to sublimate the "spirit of red candle" into the "spirit of rocket". Through constant updating technology and adding fuel, we should send ourselves to the space for travelling and add targets that more and more efficiently and precisely send into the proper orbit With the rapid development of the training base, we should further strengthen the quality education of the students, which will highlight the higher theoretical knowledge, better working quality and rapid progress of the demonstrative higher vocational college students in the employer. Build a good image of the demonstrative colleges and universities to bring the virtuous cycle of employment and truly achieve the demonstration of employment. It is necessary to accelerate the exploration, to form the management and operation mode of entrepreneurship education with unique vocation characteristics, and promote the scientific development of contemporary vocational entrepreneurship education [6]. For the construction of more mature demonstrative higher vocational colleges, great efforts should be made to highlight the demonstration and the characteristics of strong hands-on ability of the higher vocational college students. Only in this way, can students in demonstrative higher vocational colleges always walk in the forefront of the vocational colleges for a long time. Even in face of complex changes in employment situation, they can always be favored by employers so as to show the demonstration of employment in demonstrative higher vocational colleges. 


\section{Strengthen the Optimization of Innovative Teachers' Resources, Show Demonstration of the Innovative Development}

Current situation: some schools systems limit teachers' passion for innovation, and some teachers do not really understand the connotation of "subversive innovation", often ignoring the current situation and only seeking "new ways". American scholar $\mathrm{C} \cdot \mathrm{W} \cdot$ Morris once metaphorically said that ideas are the atomic bombs of human culture, and the ideas come from people who have thought and can speak and write well. That is to say, the power of ideas is very huge, which can not only hinder the transformation of society but also push society forward. The difference lies in what kind of ideas people hold, that is, what kind of ideas occupy the main body of thought. Ideas are the precursors to behaviors, what kinds of ideas create what kinds of behaviors, and innovation without thinking will not have innovation of action. Only when the concept of innovative education is imperceptibly influenced by every carrier can they be guided and encouraged to put innovative education into practice [7]. The suggestions are as follows: schools should provide teachers with a good environment for innovation; formulate relevant encouraging policies, guide teachers to actively participate in the wave of innovation, create a good academic atmosphere for talents to stand out and vigorously promote the spirit of innovation under the premise of fair and open competition; have the courage to employ "young" innovative teachers, form a fierce competition for construction in the whole school, and create conditions to train teachers to be creative, imparting, and applied experts.

\section{CONCLUSION}

"Forge ahead like a gigantic ship breaking through strong winds and heavy waves". Higher vocational education should adhere to the scientific concept of development, continue to adhere to the strategy of all-round, balanced and sustainable development, strive to build the demonstrative higher vocational education brand, and ensure that education can meet the needs of the people. Teachers should renew their ideas, further free their minds, reform and innovate, and try to be innovative teachers. We should always grasp a core-giving full play to the baton of the test, to ensure the learning atmosphere of the all students. We should improve the management level of the colleges to guarantee the stable and efficient work of each college. We should aim at cultivating dedicated, innovative and applied talents. We should profoundly understand and apply the dialectical relationship of "using employment to promote development and using development to promote employment". All our efforts guarantee the sustainable and steady development of demonstrative higher vocational education.

\section{ACKNOWLEDGMENT}

Chongqing vocational institute of engineering "top ten education" quality project, "intelligent civil engineering"exploring the new mode of integration of industry and education under the strategy of transportation power. Higher vocational education double base construction project of chongqing municipal education committee: chongqing vocational institute of engineering construction engineering technology specialty (group) double base construction project.

\section{REFERENCES}

[1] D.Y. Jiang, Ecological Strategy of Building Harmonious Education, Issue No. 8, vol. 23. Studies in Dialectics of Nature, 2007, pp.103104.(In Chinese).

[2] M.W. Li, Harmonious symbiotic mechanism of campus natural ecological culture and educational ecological culture, Issue No. 8. Course Education Research, 2020, pp.11-12. (In Chinese).

[3] G.Q. Jin, Building Harmonious Campus and Developing Harmonious Education, Issue No. 5, vol. 16. Journal of Kangding Nationality Teachers College, 2006, pp.57-59. (In Chinese).

[4] Y. T. He, The Construction of Harmonious Campus to Achieve the Comprehensive and Coordinated Development of Higher Education in China, Issue No. 8. Extensive Collection of The Party History, 2012, pp.59-61. (In Chinese).

[5] Z.P. ZENG, Reflections on Part-time Counselor Work for Professional Teachers in Colleges and Universities, Issue No. 6. Guangdong Vocational Technical Education and Research, 2019, pp.133-135. (In Chinese).

[6] Y J. Han Innovation of Management Mechanism of Entrepreneurship Education in Colleges and Universities from the Perspective of Comparative Studies, Issue No. 15. China Adult Education, 2012, pp.1215. (In Chinese).

[7] J.F. Zhang,Contemporary Construction of Operation Mechanism of Innovative Education in Colleges and Universities, Issue No. 3. Forward Position, 2008, pp.44-47. (In Chinese) 